\title{
Care Gaps in the Electronic Discharge Medication Reconciliation Process at an Acute Care Facility
}

\author{
Kelly MacDonald, Marsha Cusack, Su Qiong Rebecca Liang, and Kilby Rinco
}

\begin{abstract}
Background: Many patients experience adverse events at the time of discharge from hospital, and most of these events are medication-related. To improve patient safety, Health PEI (the health authority for Prince Edward Island) has made medication reconciliation a priority. The Queen Elizabeth Hospital in Charlottetown is one of the few Canadian hospitals with an electronic discharge process. A discharge report has been developed to provide pertinent information to patients at discharge, including a final medication list to be shared with the community pharmacy at the patient's discretion.
\end{abstract}

Objective: To identify care gaps related to the transfer of information for the medication reconciliation part of the electronic discharge process at the Queen Elizabeth Hospital.

Methods: The study was conducted on 4 nursing units offering medical and surgical services. Data for the 8-week prospective study (June to August 2016) were collected using a study-specific discharge evaluation checklist and hospital-to-community pharmacy feedback form. All inpatients 65 years of age or older with a hospital stay longer than 4 days who were receiving more than 5 medications on discharge were eligible to participate.

Results: During the study period, data were compiled for the 72 of 154 eligible patients who provided consent. Of these, $69(96 \%)$ had a change in medications. Follow-up showed that $12(17 \%)$ of the 72 discharge reports had reached the patient's community pharmacy; of these, 5 had been sent from a community care or long-term care facility. Fifty-four patients were discharged home, of whom 50 presented to the community pharmacy after discharge, 37 (74\%) of these on the day of discharge.

Conclusions: Most community pharmacies did not receive a discharge report from the patient or from the patient's community care or longterm care facility. This represented the largest care gap in the electronic discharge medication reconciliation process at the study hospital.

Keywords: electronic discharge, medication reconciliation, care gaps, hospital discharge

\section{RÉSUMÉ}

Contexte : Lors de leur congé de l'hôpital, bon nombre de patients subissent des événements indésirables, dont la plupart sont de nature pharmacothérapeutique. Afin d'améliorer la sécurité des patients, Santé Î.-P.-É. (la régie de santé de l'Île-du-Prince-Édouard) a fait du bilan comparatif des médicaments une priorité. L'Hôpital Queen Elizabeth, à Charlottetown, est l'un des rares établissements canadiens dotés d'un processus de congé électronique. Un rapport a été mis au point afin d'offrir de l'information pertinente aux patients au moment du congé, y compris une liste définitive des médicaments à faire parvenir à la pharmacie communautaire au gré du patient.

Objectif : Identifier les lacunes dans les soins liées au transfert d'information relative au bilan comparatif des médicaments faisant partie du processus de congé électronique à l'Hôpital Queen Elizabeth.

Méthodes : Létude a été menée dans quatre unités de soins offrant des services médicaux et chirurgicaux. Les données pour l'étude prospective d'une durée de huit semaines (de juin à août 2016) ont été recueillies à l'aide d'une liste de vérification conçue spécialement pour procéder à l'évaluation après le congé durant cette étude et d'un formulaire de rétroaction sur le transfert d'information de l'hôpital à la pharmacie communautaire. Tous les patients hospitalisés de 65 ans et plus dont le séjour était de plus de quatre jours et qui recevaient plus de cinq médicaments au moment du congé étaient admissibles à l'étude.

Résultats : Pendant la période de l'étude, des données ont été recueillies auprès de 72 des 154 patients admissibles ayant donné leur accord. Parmi ceux-ci, 69 (96\%) ont connu un changement à leur pharmacothérapie. Un suivi a montré que $12(17 \%)$ des 72 rapports de congé ont été reçus par la pharmacie communautaire du patient; parmi ceux-ci, cinq ont été envoyés à partir d'un établissement de soins communautaires ou de soins de longue durée. Cinquante-quatre patients sont retournés à leur domicile après leur congé; 50 d'entre eux se sont présentés à la pharmacie communautaire et 37 (74\%) de ce groupe ont fait cette visite le jour du congé.

Conclusion : La plupart des pharmacies communautaires n'ont pas reçu le rapport de congé de la part du patient ou de son établissement de soins communautaires ou de soins de longue durée. Il s'agissait de la plus importante lacune dans les soins concernant le processus électronique de bilan comparatif des médicaments au moment du congé à l'hôpital où s'est déroulée l'étude.

Mots clés : processus de congé électronique, bilan comparatif des médicaments, lacunes dans les soins, congé de l'hôpital 


\section{INTRODUCTION}

$\mathrm{E}^{\mathrm{v}}$ very day, thousands of patients are discharged from Canadian acute care facilities. A robust discharge process is essential to ensure a seamless transition, whether the patients are returning home or moving to an alternate level of care. The process is multifaceted, involving a variety of health care professionals, and is often, therefore, a source of discrepancies and errors. ${ }^{1}$ Patients are especially vulnerable to adverse events during this period, when fragmentation of care and inadequate communication are common. ${ }^{2,3}$ For the purpose of this study, we refer to these discrepancies and errors in the transfer of information as care gaps.

In a study conducted at an academic teaching hospital in the United States and published in 2003, nearly 20\% of discharged patients experienced an adverse event within 2 to 5 weeks after discharge. ${ }^{4}$ Adverse drug events were the most common postdischarge complication (66\%). About $24 \%$ of the adverse drug events were considered preventable, whereas $38 \%$ could have been identified and addressed. ${ }^{4}$ A study conducted by Forster and others $^{5}$ in 2002 showed that about 23\% of patients discharged from an acute care hospital experienced an adverse event after discharge, of which $72 \%$ were medication-related.

To support the transition of patients from hospital to community, most acute care sites in Canada have implemented a formal discharge process, which often includes discharge medication reconciliation. In 2005, Accreditation Canada made medication reconciliation a priority, and medication reconciliation at transfer or discharge was introduced as a Required Organizational Practice to improve the quality and safety of health services. ${ }^{6}$

At the time of this study, the Queen Elizabeth Hospital in Charlottetown, Prince Edward Island, was one of only a few Canadian hospitals having an electronic discharge process. The process begins with collection of an electronic best possible medication history (BPMH) by a nurse or pharmacy technician. The BPMH is then used by the most responsible physician to complete medication reconciliation and create inpatient orders. Upon discharge, the most responsible physician uses the electronic discharge medication reconciliation tool to create a discharge report based on the $\mathrm{BPMH}$, admission medication reconciliation, and inpatient orders.

Development of the electronic discharge medication reconciliation process required the efforts of a multidisciplinary team. The process was implemented in fall 2015. Upon discharge, each patient is given a copy of the electronic discharge report, which includes discharge instructions, follow-up referrals and/or appointments and home treatments, 2 copies of the final medication list (one for the patient's records and the other to be given to the community pharmacy, should the patient so choose; see Appendix 1, available from www.cjhp-online.ca/index.php/ cjhp/issue/view/124/showToc), and any prescriptions required. It is recognized, however, that there is still potential for information to be missed at the time of discharge, resulting in care gaps in the discharge medication reconciliation process, despite the new workflow. It was recognized that identification of these care gaps would provide opportunities to further improve the discharge process.

A prospective study was conducted to identify potential care gaps related to the medication reconciliation portion of the electronic discharge process on 4 nursing units offering medical and surgical services at the study hospital.

\section{METHODS}

An 8-week prospective study (June to August 2016) was conducted at the Queen Elizabeth Hospital. This facility provides emergency, surgical, inpatient, and ambulatory care services. Over a 12-month period in 2015/16, the hospital had more than 9000 admissions and just under 9000 discharges. The hospital uses an electronic health record, specifically the hospital-based electronic clinical information system. This system provides real-time exchange of clinical information in the hospital setting through the computerized provider order entry system, which includes inpatient medications. Health care providers also have access to the community-based electronic drug information system, which contains information about all prescription medications dispensed from community pharmacies for the province's residents.

The study population consisted of patients considered to be at high risk of an adverse drug event, specifically elderly patients (65 years of age or older ${ }^{7}$ ) with length of stay longer than 4 days and taking more than 5 medications $^{8}$ at the time of discharge from 1 of 4 specified nursing units providing medical and surgical care at the study hospital. Patients who were transferred from one of these study units to the inpatient rehabilitation unit were also considered for inclusion, once they had been fully discharged. Potentially eligible patients who were discharged to palliative care or restorative care were excluded, because the hospital pharmacy (rather than a community pharmacy) continued to provide medications for these patients. Patients moving from the study hospital to another acute care facility were considered to be undergoing a transfer of care and were not classified as having been discharged.

Eligible patients were identified through a report generated daily from the clinical information system. One or more of the investigators (pharmacy student [S.Q.R.L.] and/or pharmacist [K.M., M.C.]) verified each patient's mental competency level with the nurse clinical lead on each unit to determine whether the patient was able to provide consent. If a patient was not able to provide consent, the person with power of attorney was approached. The investigators then provided eligible patients or their family members with both verbal and written information about the study. The study was approved by the PEI Research Ethics Board. 
For each patient who consented to participate, one investigator (S.Q.R.L.) completed the "Hospital to Home/ Alternate Level of Care (ALC): Discharge Evaluation Checklist" (Appendix 2, available from www.cjhp-online.ca/index.php/cjhp/ issue/view/124/showToc), using the patient's electronic record around the time of discharge. Once the patient had left the facility, the "Hospital to Home/Alternate Level of Care (ALC): Hospital to Community Pharmacy Feedback Form" (Appendix 3, available from www.cjhp-online.ca/index.php/cjhp/issue/view/124/showToc) was completed by means of a phone call to the patient's community pharmacy within 4 business days after the discharge. If the patient or a caregiver had not presented to the pharmacy by the time of this follow-up, a second follow-up was scheduled within the subsequent 4 days. The procedure was the same for patients who transitioned from the hospital to community care or long-term care. Community pharmacies were asked during the follow-up whether they had received a report from the residential facility rather than the patient. A maximum of 2 attempts were made to contact the patient's community pharmacy. The feedback results were compiled in an Excel spreadsheet (Microsoft, Redmond, Washington) for analysis.

The following measurable outcomes were considered in the analysis:

- number of discharge medication reconciliation reports received by community pharmacies from a patient or caregiver;

- average number of days for discharge medication reconciliation reports to reach community pharmacies;

- number of medication issues requiring community pharmacist intervention after discharge, despite the electronic medication reconciliation process (e.g., omission of prescription orders for current medications, failure to document discontinuation of medications, issues or questions about drug coverage);

- number of communications from community pharmacists to the discharging facility or prescriber required to clarify orders when discrepancies were identified.

\section{RESULTS}

During the 8-week study period, 154 patients met the inclusion criteria, of whom 72 provided consent. The mean age was 78 years (range 65-98 years). The average length of stay was 18.2 days (range 4.1-88 days). A total of 28 community pharmacies across the province were contacted for feedback. These pharmacies reported receiving a total of 12 (17\%) discharge medication reconciliation reports for study participants. Fifty-four of the study participants were discharged home, and 7 (13\%) of these participants delivered a report to the community pharmacy. An additional 11 participants were discharged to long-term care facilities, and community pharmacies received a discharge report for 1 (9\%) of these. The remaining 7 participants were discharged to community care facilities, and a discharge report was received by a community pharmacy for 4 (57\%) of these.

Of the 72 participants, $69(96 \%)$ were discharged with 1 or more changes to their medications, including new medications $(n=63)$, discontinuations $(n=44)$, and/or change in dosage or frequency of home medications $(n=40)$ (Figure 1).

Among the 50 participants who were discharged home and who had subsequent contact with the community pharmacy, most patients and/or their caregivers (37 or $74 \%$ ) presented to the community pharmacy on the day of discharge. However, in

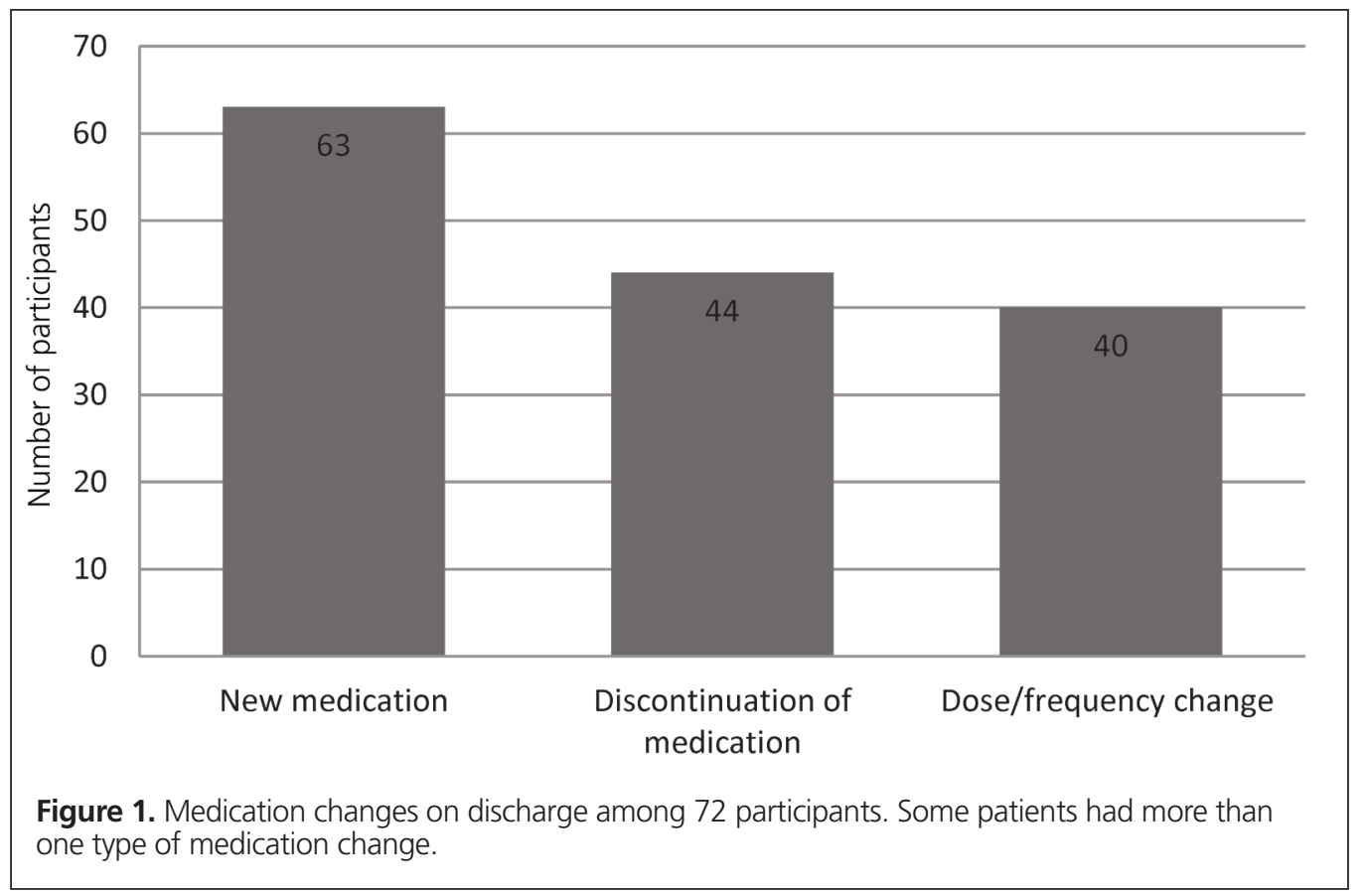




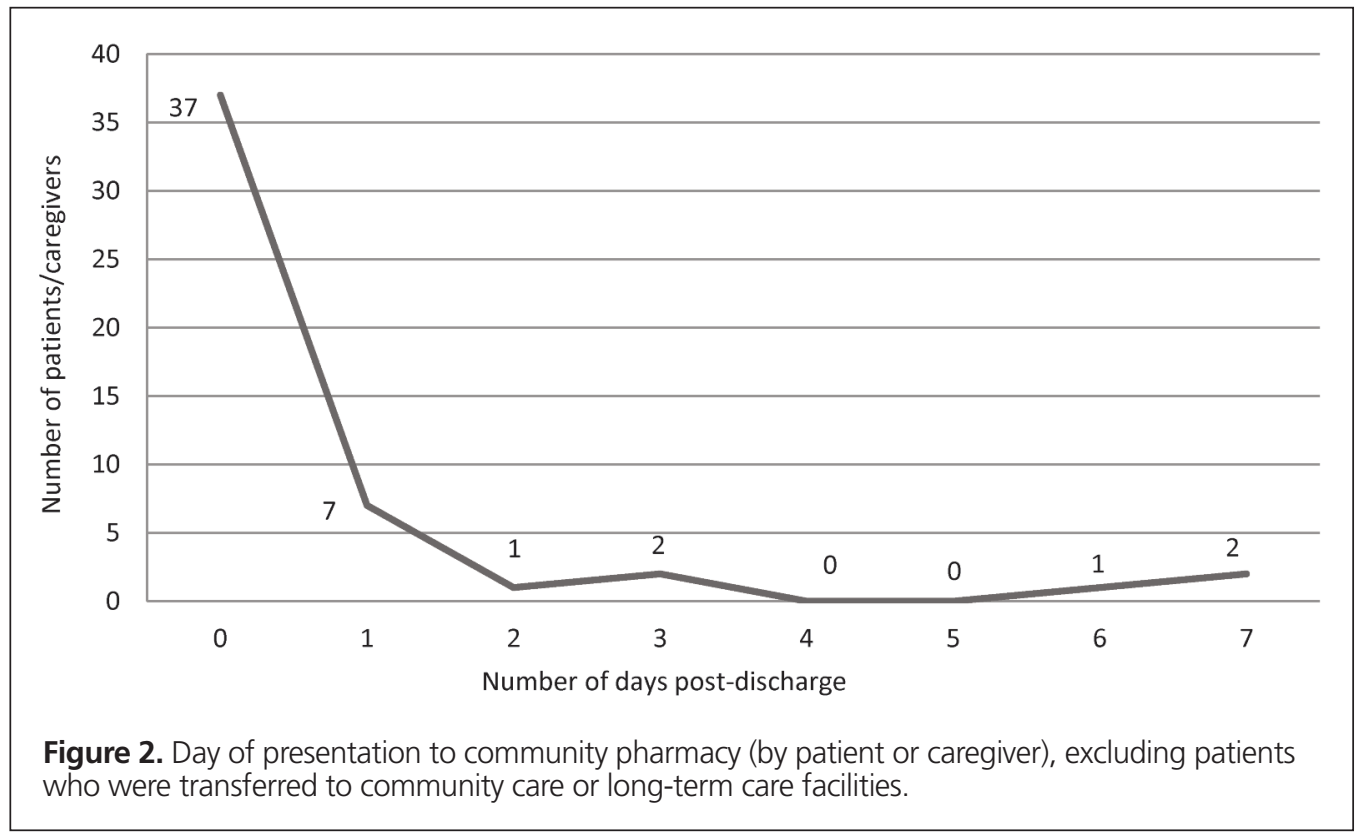

2 cases, a week elapsed before the patients had any contact with their respective pharmacies (Figure 2). All of the community care and long-term care facilities to which study participants were transferred ( $n=18$ patients) contacted a community pharmacy on the day of discharge; however, these contacts were not considered to represent "presentation" at the pharmacy.

Feedback from the community pharmacies indicated that for $12(17 \%)$ of the 72 discharges, information other than the discharge report was missing or unclear. Examples included lack of information about the status of applications for exceptional drug requests, missing prescriptions, unclear prescriptions, and missing information about the last dose of medication in the hospital. For 16 (22\%) of the 72 discharges, the community pharmacist had to contact the hospital unit, a hospital pharmacist, a physician, or a community care or long-term care facility to obtain or clarify information.

\section{DISCUSSION}

The Queen Elizabeth Hospital in Charlottetown and Health PEI (the provincial health authority) have emphasized improving the discharge process by implementing an electronic discharge process, which includes discharge medication reconciliation. Medication reconciliation at discharge is also a safety priority recognized by Accreditation Canada. It was expected that reports generated through discharge medication reconciliation would provide up-to-date medication-related information to both patients and their community pharmacies. This information would include medications that had been discontinued, changed, or added to the patient's final medication list. However, the results of this study indicate that the discharge reports are not reaching community pharmacies as expected. More specifically, patients and/or their caregivers are not taking the hospital discharge reports to their community pharmacies after discharge. Consequently, community pharmacists may not be aware of changes to medication therapy made in hospital.

The objective of this study was to identify the number and types of care gaps related to the medication reconciliation portion of the electronic discharge process. We found that in most cases, community pharmacies did not receive the final medication list. The final medication list is the component of the discharge report that identifies medication discrepancies since the time of admission. The majority (74\%) of patients and/or their caregivers did present to the pharmacy on the day of discharge to have discharge prescriptions filled. However, because the pharmacy did not receive the final medication list in the majority of cases, community pharmacists did not have the information required to identify care gaps. For example, among the 11 patients who transitioned to long-term care facilities, a final medication list was received by the community pharmacy for only 1 person. Among the 7 patients who transitioned to community care facilities, the final medication list was received by the community pharmacy for only 4. However, in all cases of transition to long-term care or community care, the patient's prescriptions were faxed to the community pharmacy on the day of discharge. Thus, the pharmacies had the discharge prescriptions, but did not receive background information about changes to prescriptions during the hospital stay. As a result of this failure in having the final medication list reach community pharmacies, community pharmacists could not comment on the care gaps that might have existed.

The study had some potential limitations. Because community pharmacists did not often receive the final medication list, the 
investigators were unable to determine the types and severity of care gaps that existed at discharge. Further study in this area would be valuable. During follow-up with the community pharmacies, the pharmacist providing feedback to the investigators was often not the pharmacist who interacted with the patient and/or caregiver at the time of presentation to the community pharmacy. As a result, some issues may not have been clearly documented, and the feedback received by investigators may have been incomplete. Finally, many of the patients who met the initial inclusion criteria were unable to provide consent and therefore could not be included in the study.

\section{CONCLUSION}

For patients included in this study, most community pharmacies did not receive the final medication list from the patient or caregiver (as provided at the time of discharge), despite the fact that the patient and/or caregiver presented to the community pharmacy on the day of discharge. Final medication lists were also rarely received from long-term care facilities. According to these results, the largest care gap in the discharge medication reconciliation process on the 4 nursing units involved in this study was the failure of final medication lists to reach community pharmacies. The substantial number of medication changes on discharge identified in this study indicates the significant value of providing accurate and complete medication information to the community pharmacist upon discharge. The data generated by this study, when disseminated to health authorities, will help guide future training strategies that pertain to the discharge medication reconciliation process, in particular the importance of having a defined process to communicate medication information to community providers upon discharge.

Given the results of this study, the Queen Elizabeth Hospital may reconsider the method by which the final medication list component of discharge reports is delivered to community pharmacies. This study highlighted the lack of a clearly defined process for dissemination of medication discharge information. Once this issue is addressed, further research could be conducted to identify care gaps related to the electronic discharge medication reconciliation process.

\section{References}

1. Herrero-Herrero JI, García-Aparicio J. Medication discrepancies at discharge from an internal medicine service. Eur J Intern Med. 2011;22(1):43-8.

2. Naylor M, Keating SA. Transitional care. Am J Nurs. 2008;108(9 Suppl): 58-63; quiz 63.
3. Kripalani S, LeFevre F, Phillips CO, Williams MV, Basaviah P, Baker DW. Deficits in communication and information transfer between hospital-based and primary care physicians: implications for patient safety and continuity of care. JAMA. 2007;297(8):831-41.

4. Forster AJ, Murff HJ, Peterson JF, Gandhi TK, Bates DW. The incidence and severity of adverse events affecting patients after discharge from the hospital. Ann Intern Med. 2003;138(3):161-7.

5. Forster AJ, Clark HD, Menard A, Dupuis N, Chernish R, Chandok N, et al. Adverse events among medical patients after discharge from hospital. CMAJ. 2004;170(3):345-9.

6. Accreditation Canada. Canadian Institute for Health Information, Canadian Patient Safety Institute, Institute for Safe Medication Practices Canada. Medication reconciliation in Canada: raising the bar. Progress to date and the course ahead. Ottawa (ON): Accreditation Canada; 2012.

7. Orimo H, Ito H, Suzuki T, Araki A, Hosoi T, Sawabe M. Reviewing the definition of "elderly." Geriatr Gerontol Int. 2006;6(3):149-58.

8. Hospital to home-facilitating medication safety at transitions (a toolkit for healthcare providers). Toronto (ON): Institute for Safe Medication Practices Canada; 2015 [cited 2015 Aug 27]. Available from: www.ismp-canada.org/ transitions/download-toolkit.php

Kelly MacDonald, BScPharm, is a Pharmacist with Queen Elizabeth Hospital, Charlottetown, Prince Edward Island.

Marsha Cusack, BScPharm, is the Provincial Order Set Analyst for Health PEl, based at Queen Elizabeth Hospital, Charlottetown, Prince Edward Island.

Su Qiong Rebecca Liang, BScPharm, was, at the time of this study, a pharmacy student with Queen Elizabeth Hospital, Charlottetown, Prince Edward Island. She is now a Pharmacy Practice Resident with Lower Mainland Pharmacy Services, Vancouver, British Columbia.

Kilby Rinco, BScPharm, ACPR, is the Pharmacy Manager for Queen Elizabeth Hospital, Hillsborough Hospital (Charlottetown), Kings County Memorial Hospital (Montague), and Souris Hospital (Souris), Prince Edward Island.

Competing interests: Kilby Rinco is a member of the Board of the Dalhousie Pharmacy Endowment Fund, which supported this study. No other competing interests were declared.

\section{Address correspondence to: \\ Kelly MacDonald \\ Queen Elizabeth Hospital \\ PO Box 6600 \\ Charlottetown PE C1B 8T5}

e-mail: kkmacdonald@ihis.org

Funding: This project was supported by a research grant from the Dalhousie Pharmacy Endowment Fund 2015.

Acknowledgements: The authors would like to thank Nursing Units 1, 2, 3, and 8 at the Queen Elizabeth Hospital, as well as several pharmacists in the study hospital and in community pharmacies, for their assistance and support throughout the study. 